\title{
Avaliação de Desempenho de Sistemas de Saúde: um modelo de análise
}

\author{
Evaluation of performance of health systems: a model for analysis
}

Francisco Viacava ${ }^{1}$

Maria Alicia Domínguez Ugá ${ }^{2}$

Silvia Porto ${ }^{2}$

Josué Laguardia ${ }^{1}$

Rodrigo da Silva Moreira ${ }^{1}$

${ }^{1}$ Instituto de Comunicação e Informação Científica e Tecnológica em Saúde (ICICT), Fundação Oswaldo Cruz. Av. Brasil 4.365/Pavilhão Haity Moussatché, Manguinhos. 3865-3242 Rio de Janeiro RJ.viacava@icict.fiocruz,br ${ }^{2}$ Escola Nacional de Saúde Pública Sérgio Arouca, Fundação Oswaldo Cruz.
Abstract This paper presents a review of the Dimension Matrix for Evaluation of the Brazilian Health System that was initially developed in 2003, as well as a conceptual update of some of the sub-dimensions for the evaluation of health service performance, namely effectiveness, access, efficiency and appropriateness of health care. It also describes the indicator selection process as well as the results obtained in each performance dimension. The behavior of the indicators used to assess the performance of health services in Brazil, with respect to each sub-dimension, was not uniform. Areas of marked improvement were found in indicators that are influenced by activities in the field of primary care. The most significant improvements were seen in the sub-dimensions of Effectiveness and Access. With respect to the Efficiency of health services, situations of high efficiency coexist with others with substandard performance. The performance of health services in the sub-dimension of Appropriateness of Health Care was the lowest of all indicators.

Key words Health system performance, Efficiency, Effectiveness, Access, Appropriateness of health care
Resumo Este artigo apresenta uma revisão da Matriz de Dimensões da Avaliação do Sistema de Saúde no Brasil desenvolvida em 2003, e uma atualização conceitual de parte das subdimensões de avaliação do desempenho dos serviços de saúde: efetividade, acesso, eficiência e adequação. Descreve o processo de seleção dos indicadores utilizados e uma sintese dos resultados para cada subdimensão do desempenho. O comportamento dos indicadores utilizados para avaliar o desempenho dos serviços de saúde no Brasil, no que se refere às quatro subdimensões selecionadas, não é uniforme e as melhorias mais acentuadas são observadas naquelas influenciadas pela atuação dos serviços no campo da atenção primária, as melhorias mais significativas foram observadas nas Efetividade e Acesso. Em relação à Eficiência dos serviços de saúde coexistem situações de alta eficiência com outras de baixo desempenho. A atuação dos serviços de saúde na subdimensão Adequação foi pior do que nas demais apresentadas. Palavras-chave Desempenho do sistema de saúde, Eficiência, Efetividade, Acesso, Adequação 


\section{Introdução}

Na proposta formulada pelo Projeto de Avaliação de Desempenho de Sistemas de Saúde (PROADESS), o desempenho dos serviços de saúde está fortemente associado à estrutura do sistema, na qual a arquitetura e o funcionamento deveriam ser capazes de garantir o atendimento das necessidades de saúde, decorrentes, em grande parte, de determinantes sociais, políticos e econômicos. Nesse modelo, tanto o arcabouço político, social e econômico como a conformação do sistema são condicionantes fundamentais que permeiam todo o seu funcionamento e adquirem caráter contextual no processo de avaliação do desempenho. Na primeira etapa do projeto, encerrada em 2003, foi elaborada uma matriz de análise, contendo as definições conceituais das distintas dimensões que a compõem, bem como uma lista de indicadores, sempre que possível baseada na experiência internacional ${ }^{1}$.

Em 2008, sob o estímulo do Ministério da Saúde, foi dada continuidade ao desenvolvimento do projeto, empreendendo-se uma revisão da matriz e dos conceitos a ela subjacentes, com especial ênfase nos componentes da dimensão desempenho de serviços de saúde. Além disso, procedeu-se à seleção de um conjunto de indicadores para cada subdimensão, a partir da revisão dos indicadores propostos em 2003.

Este artigo apresenta uma revisão conceitual de parte das subdimensões de avaliação do desempenho dos serviços de saúde - efetividade, acesso, eficiência e adequação - bem como o processo de seleção de seus respectivos indicadores sugeridos na segunda etapa do PROADESS e uma síntese dos resultados obtidos.

\section{Revisão conceitual do modelo e das subdimensões analisadas}

Com relação à matriz conceitual original, a principal mudança realizada na segunda etapa do projeto diz respeito ao deslocamento da subdimensão "Condução do Sistema de Saúde", que deixou de ser um elemento da estrutura do sistema de saúde, ao lado de "Financiamento" e "Recursos", passando a um nível acima da própria estrutura, entendendo-se que expressa o contexto político e define ou modela essas outras subdimensões. (Figura 1)

No que diz respeito à conceituação das subdimensões dessa matriz, apresentamos aqui somente a daquelas em relação às quais são apresentados resultados neste artigo. São elas: Efetividade, Acesso, Eficiência e Adequação.

\section{Efetividade}

Nas últimas décadas, a efetividade vem sendo progressivamente relacionada com os resultados em saúde, alcançados através de uma determinada intervenção.

Facchini et al. ${ }^{2}$ referem que, embora seja frequente a imprecisão em torno dos conceitos de eficácia, de eficiência e, até mesmo, de qualidade, prevalece uma forte tendência a relacionar a efetividade com o "efeito das ações e práticas de saúde implementadas".

Para Vuori ${ }^{3}$, a efetividade diz respeito à relação entre os impactos real e potencial do serviço em uma situação ideal determinada. Em perspectiva análoga, Donabedian ${ }^{4}$ pontua que um conceito subjacente a esta dimensão é o de eficácia, que é o grau com que uma determinada intervenção produz um determinado impacto em uma situação ideal.

A Joint Commission on Accreditation of Healthcare Organizations (JCAHO $)^{5}$ define efetividade como o grau com que uma determinada intervenção ou tecnologia médica traz benefícios para indivíduos de uma população definida, sob condições regulares de uso. A efetividade e o impacto estariam, portanto, relacionados às modificações introduzidas por uma intervenção num contexto da vida real. Para o Committee on Quality of Health Care in America ${ }^{6}$, a efetividade constitui um atributo do cuidado que é baseado no uso de evidências sistematicamente adquiridas para determinar se uma intervenção específica produz melhores resultados do que outras possibilidades de ação, incluindo a alternativa de não fazer nada.

As acepções elaboradas pelos diversos autores convergem para a ideia anteriormente adotada pelo PROADESS, segundo a qual efetividade é o grau com que a assistência, os serviços e as ações atingem os resultados esperados.

\section{Acesso}

No campo da saúde, o acesso está relacionado com as facilidades e as dificuldades em obter tratamento desejado, estando, portanto, intrinsecamente ligado às características da oferta e da disponibilidade de recursos ${ }^{7}$. O que está, portanto, em pauta é a possibilidade de obter serviços necessários no momento e no local adequados, em quantidade suficiente e a um custo razoável. Ou seja, a garantia de acesso pressupõe a remoção de obstáculos físicos, financeiros e outros para a utilização dos serviços disponíveis. A JCAHO incorpora uma subdimensão do acesso, que se refere à ideia de tempo oportuno (timeli- 


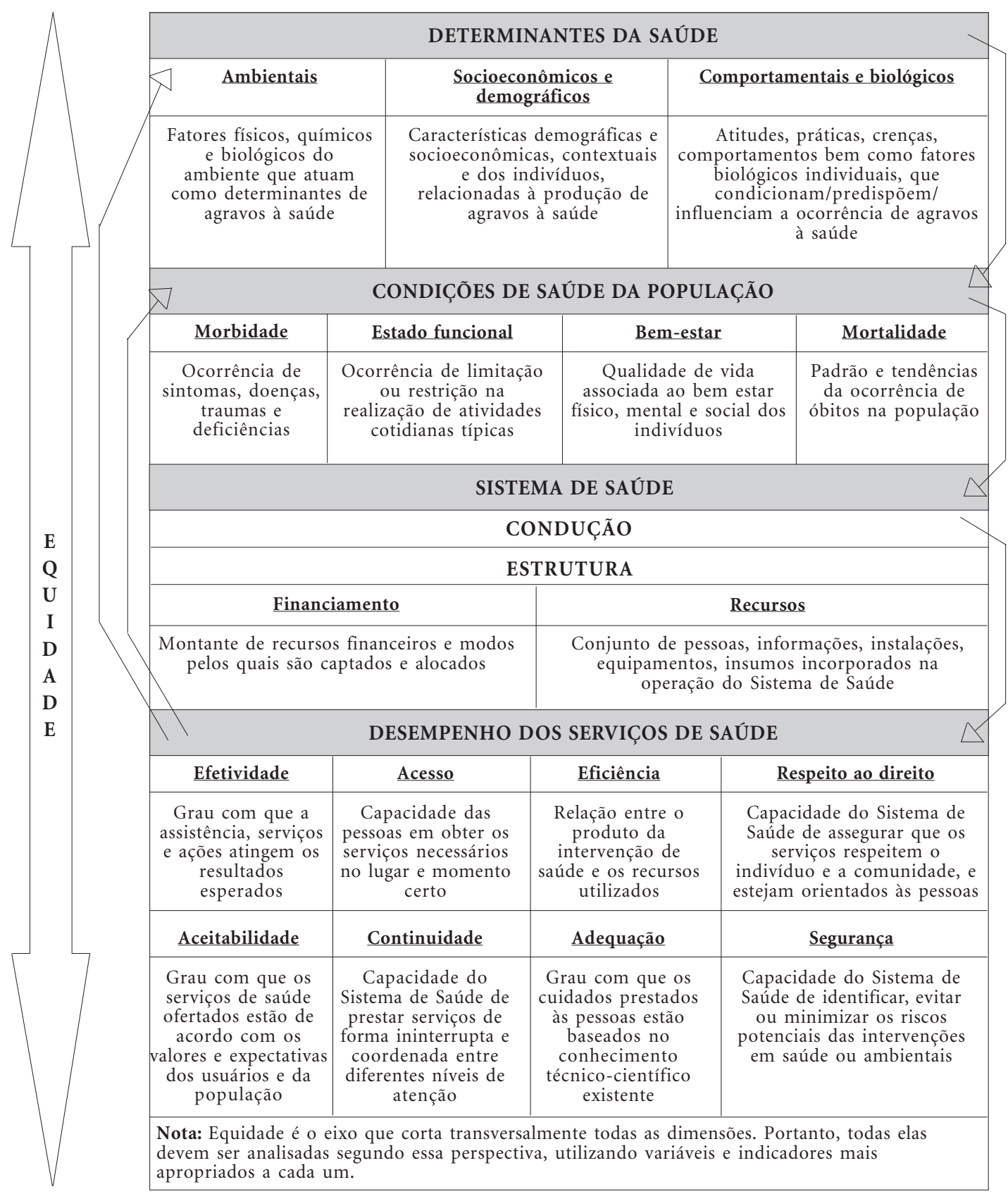

Figura 1. Matriz das dimensões da avaliação do sistema de saúde proposta pelo PRO-ADESS

ness), que é o período durante o qual a prestação do cuidado se faz mais benéfica e necessária.

Donabedian $^{8}$ denomina acessibilidade ao conjunto de fatores que intervêm entre a capacidade real ou potencial de produzir serviços e a capacidade, também real e potencial, de consumo dos mesmos. Assim, acessibilidade passa a ser vista além da presença e da disponibilidade de recursos em um determinado lugar e num tempo dado, uma vez que sua definição engloba as características dos recursos que facilitam e obstruem o uso por clientes potenciais. Para esse autor, a acessibilidade está subdividida em sócio-organizacional e geográfica. 
Para o Observatório Europeu de Saúde, o acesso a serviços de saúde constitui pré-condição de cidadania, sendo consensual que sua distribuição obedeça às necessidades de saúde. Segundo os propositores desta definição, duas modalidades de acesso têm balizado a discussão sobre o tema: o acesso a um pacote mínimo de benefícios e o equitativo?.

No senso comum, acesso e acessibilidade são conceitos muitas vezes tratados de forma indistinta. Apesar disso também acontecer na literatura acadêmica, alguns autores marcam a diferenciação entre eles. Para alguns, a acessibilidade é uma das dimensões do acesso, que se refere à distância geográfica, tempo e custo. Há ainda quem trabalhe com esses conceitos de forma relacional, onde acesso ou acessibilidade diz respeito ao grau de ajuste entre as características da população e da oferta de serviços.

A literatura científica aponta uma ampliação do conceito de acesso, cuja ênfase se desloca da ideia anterior de entrada nos serviços para a dos resultados dos cuidados recebidos. Reforça-se a necessidade de se manter as distinções entre acesso e uso de serviços; e entre acesso, efetividade e continuidade dos cuidados prestados. A avaliação do acesso deve ser feita separadamente, segundo os tipos de cuidado, tipos de serviços e nível de atenção (atenção primária, especializada e de alta complexidade), pois tais diferenciações caracterizam situações e fatores distintos que influenciam o acesso ${ }^{10}$.

A natureza multidimensional dos conceitos de acesso e acessibilidade pode ser vista segundo as dimensões técnica, econômica, política e simbólica ${ }^{11}$. A dimensão técnica compreende os aspectos mais restritos à entrada inicial nos serviços e à forma como a oferta destes está organizada. A dimensão econômica envolve questões concernentes ao acesso potencial. No campo político, a equidade e a universalidade do acesso a todos os níveis de atenção são princípios que devem nortear as políticas de saúde e o modelo de atenção. Na dimensão simbólica, estão incluídas as percepções, as concepções e a atuação dos sujeitos, as representações sociais sobre o processo saúde-doença, e a forma como o sistema de saúde se organiza para atender as necessidades.

Na matriz conceitual do PROADESS, acesso é definido como a capacidade do sistema de saúde em prover o cuidado e o serviço necessário, no momento certo e no lugar adequado.

\section{Eficiência}

A eficiência em saúde é pensada como a relação entre o custo e o impacto dos serviços sobre a saúde da população, mantido um nível de qualidade determinado.

Nessa direção, Donabedian ${ }^{8}$ define a eficiência como a relação entre o impacto real de um serviço ou programa (efetividade) e seu custo.

Com base na revisão sistemática de artigos sobre mensuração da eficiência dos cuidados de saúde publicados entre 1990 e 2008, Hussey et al. ${ }^{12}$ verificaram que quase todos os indicadores utilizados não consideravam explicitamente a qualidade dos cuidados e que a maior parte deles refletia apenas os custos dos mesmos, desconsiderando questões inerentes à qualidade.

Segundo Binder et al. ${ }^{13}$, além dos insumos e dos custos envolvidos na produção dos cuidados de saúde, outros fatores intervêm na eficiência - a necessidade e a adequação do tratamento e a efetividade dos resultados. Neste sentido, um indicador de ineficiência são as internações por procedimentos factíveis em nível ambulatorial ou as taxas de internações evitáveis ${ }^{14}$.

O tempo médio de permanência e a taxa de ocupação dos leitos podem indicar eficiência. Entretanto, análises baseadas nessas medidas devem considerar também aspectos relacionados a características dos pacientes e ao nível de complexidade dos procedimentos.

Da mesma forma que a $\mathrm{JCAHO}^{15} \mathrm{e}$ a $\mathrm{OECD}^{16}$, o PROADESS define eficiência como a otimização dos recursos disponíveis para produzir o máximo de benefícios e resultados.

\section{Adequação}

A conceituação da adequação do cuidado considera a disponibilidade de serviços segundo as necessidades da população, definidas em termos de quantidade, distribuição espacial e emprego das melhores práticas ${ }^{17}$. Ela pode também abranger o conceito de qualidade do cuidado, ou seja, o grau com que os serviços de saúde para indivíduos e populações aumentam a probabilidade de obter resultados de saúde esperados e consistentes com o conhecimento profissional atual $^{18-19}$.

Outros autores propõem que a análise da adequação do cuidado à saúde considere o emprego das melhores práticas, bem como se as ações estão baseadas em conhecimentos tecnológicos bem fundamentados ${ }^{20}$. 
Tradicionalmente, um procedimento, ou uma intervenção, é considerado adequado quando os benefícios esperados excedem as consequências negativas por uma margem suficientemente ampla que torne válida sua realização $0^{21}$.

Em contraposição à tendência de considerar a adequação em termos estritamente de evidência clínica, alguns autores assinalam que a avaliação inerente à adequação tem espectro mais amplo, compreendendo os valores da ciência, da medicina, dos indivíduos e da sociedade. O cuidado apropriado depende do profissional consultado, dos locais de moradia e trabalho, do peso conferido aos diferentes tipos de evidências e desfechos, da consideração, ou não, das preferências dos pacientes e seus familiares, dos recursos disponíveis em um determinado sistema de saúde, e dos valores prevalentes no sistema e na sociedade em que o cuidado é provido ${ }^{22}$.

Há autores que enfatizam as questões éticas na definição de adequação do cuidado ${ }^{23-24}$, e as decisões visando o melhor custo-efetividade devem ser baseadas na solidariedade social e no processo de identificação das práticas mais adequadas em uma determinada sociedade. A sintonia entre os serviços, o conhecimento e as tecnologias disponíveis deve ser modelada de acordo com os princípios éticos e as restrições dadas pelos recursos humanos, financeiros e de equipamentos disponíveis. Embora a definição de adequação apresente maior variação conceitual quando comparado às outras subdimensões de desempenho dos serviços de saúde, e muito frequentemente seja apresentada como parte da efetivida$\mathrm{de}^{25}$, a revisão sistemática da literatura ${ }^{26}$ mostra que $40 \%$ dos modelos teóricos de avaliação de desempenho incluem a adequação no nível de sistema de saúde, definido como um conjunto de organizações/instituições. Nesse sentido, a adequação estaria incluída no grupo dos indicadores de provisão de serviços e, com base em evidências e padrões, representaria o melhor ajuste dos serviços com as necessidades dos clientes.

Nessa mesma vertente, o conceito de adequação adotado pela $\mathrm{JCAHO}^{14}$ considera o grau de relevância de uma intervenção ou o cuidado prestado para as necessidades clínicas dos pacientes, dados o conhecimento existente e o uso de práticas baseadas em conhecimentos técnicos bem fundamentados. No âmbito do PROADESS, a adequação é definida como o grau com que os cuidados prestados às pessoas estão baseados nos conhecimentos técnico-científicos bem fundamentados existentes.

\section{Seleção dos indicadores}

A partir da revisão das matrizes de indicadores do CIHI e AIHW e daqueles propostos pelo PROADESS, obteve-se uma lista de cerca de 250 indicadores relativos à dimensão Desempenho dos Serviços de Saúde. Estes foram submetidos a uma análise tendo como base sua validade de face e a viabilidade de obtenção dos dados. Para reduzir o número final de indicadores, foi realizada uma avaliação da redundância, tendo em vista as fontes de informação e, com isso, foram agregados os indicadores que muitas vezes se diferenciavam apenas pela seleção de grupos etários, procedimentos, ou ainda por pequenas alterações no método de cálculo.

Ao final desse processo foram selecionados para todas as dimensões da matriz conceitual 113 indicadores, elaborando-se suas respectivas fichas técnicas. Sempre que possível, priorizaramse os indicadores já formulados e/ou calculados por outras instituições, como os Indicadores Básicos de Saúde (IDBs) da RIPSA/DATASUS, VIGITEL, IPEADATA e IBGE.

Estes indicadores estão disponíveis na nova página eletrônica do PROADESS ${ }^{27}$, que apresenta a Matriz Conceitual, a de Indicadores e Biblioteca do Projeto.

O tratamento estatístico dos dados variou em função das fontes de dados e operou com recortes segundo sexo, idade, abrangência geográfica e, quando viável, variáveis socioeconômicas (escolaridade e renda). Os indicadores selecionados e as fontes de informação utilizadas em cada caso estão indicadas na Tabela 1.

Considerando a necessidade de analisar séries históricas e, sempre que possível, comparar os dados das diferentes unidades da federação, decidiu-se que, quando as taxas de internação hospitalar fossem calculadas a partir da fonte primária, seriam obtidas as taxas brutas e as padronizadas por idade e sexo, usando o método direto e tomando como referência a população brasileira de 2000. Todos os indicadores de determinantes de saúde e condições de saúde, assim como os indicadores das subdimensões acesso e efetividade estão referidos ao local de residência das pessoas.

No caso das pesquisas amostrais, foi possível calcular os indicadores para grupos populacionais definidos a partir de sexo, escolaridade, quintil de renda familiar per capita e situação urbano/ rural. As estimativas foram calculadas levandose em conta os pesos e o desenho amostral e são acompanhadas dos intervalos de confiança 95\%. 
Tabela 1. Valores médios dos indicadores selecionados para avaliação de desempenho dos serviços de saúde no Brasil

\begin{tabular}{|c|c|c|c|c|c|c|c|}
\hline & 1998 & 1999 & 2000 & 2001 & 2002 & 2003 & 2004 \\
\hline \multicolumn{8}{|c|}{ Efetividade } \\
\hline \multicolumn{8}{|l|}{ Mortes evitáveis } \\
\hline $\begin{array}{l}\text { Taxa de mortalidade por hipertensão } \\
\text { padronizada pos sexo e idade para cada } 100 \\
\text { mil habitantes ( } 50 \text { a } 64 \text { anos) }\end{array}$ & 32,5 & 35,3 & 32,6 & 31,8 & 31,8 & 33,4 & 34,9 \\
\hline $\begin{array}{l}\text { Taxa de mortalidade por diabete melito } \\
\text { padronizada por sexo e idade para cada } 100 \\
\text { mil habitantes com ( } 30 \text { anos ou mais) }\end{array}$ & 43,9 & 48,8 & 48,5 & 46,9 & 47,9 & 47,8 & 47,8 \\
\hline $\begin{array}{l}\text { Taxa de mortalidade por diarreia para cada } \\
100 \text { mil habitantes menores de } 5 \text { anos. }\end{array}$ & 35,7 & 27,5 & 22,0 & 19,5 & 18,8 & 17,8 & 15,5 \\
\hline $\begin{array}{l}\text { Taxa de mortalidade por IRA para cada } 100 \\
\text { mil crianças menores de } 5 \text { anos. }\end{array}$ & 37,0 & 31,9 & 28,8 & 24,6 & 22,1 & 22,7 & 21,2 \\
\hline \multicolumn{8}{|l|}{ Incidência de doenças evitáveis } \\
\hline $\begin{array}{l}\text { Taxa de incidência de AIDS para cada } 100 \\
\text { mil habitantes. }\end{array}$ & 18,7 & 16,9 & 17,8 & 18,2 & 21,5 & 21,0 & 20,0 \\
\hline $\begin{array}{l}\text { Taxa de incidência de tuberculose para cada } \\
100 \text { mil habitantes. }\end{array}$ & - & - & - & 42,8 & 44,4 & 44,4 & 42,8 \\
\hline \multicolumn{8}{|l|}{$\begin{array}{l}\text { Internações evitáveis por condições sensíveis à } \\
\text { atenção primária }\end{array}$} \\
\hline $\begin{array}{l}\text { Percentual de internações por Condições } \\
\text { Sensíveis à Atenção Primária (todas as } \\
\text { condições). }\end{array}$ & 24,7 & 25,4 & 24,9 & 25,2 & 25,8 & 26,1 & 25,3 \\
\hline $\begin{array}{l}\text { Taxa de internação por gastroenterite } \\
\text { padronizada por sexo e idade para cada } 100 \\
\text { mil habitantes. }\end{array}$ & 337,5 & 344,3 & 317,5 & 331,9 & 343,9 & 343,1 & 306,1 \\
\hline $\begin{array}{l}\text { Taxa de internação por insuficiência cardíaca } \\
\text { padronizada por sexo e idade para cada } 100 \\
\text { mil habitantes com } 40 \text { anos ou mais. }\end{array}$ & 1097,2 & 1178,5 & 1013,6 & 958,4 & 907,9 & 850,4 & 774,7 \\
\hline $\begin{array}{l}\text { Taxa de internação por asma padronizada por } \\
\text { sexo e idade para cada } 100 \text { mil habitantes. }\end{array}$ & 223,7 & 239,2 & 234,0 & 213,2 & 217,4 & 197,8 & 185,2 \\
\hline $\begin{array}{l}\text { Taxa de internação por pneumonia } \\
\text { bacteriana padronizada por sexo e idade para } \\
\text { cada } 100 \text { mil habitantes ( } 18 \text { anos ou mais) }\end{array}$ & 74,5 & 68,4 & 58,4 & 55,8 & 42,1 & 55,8 & 60,0 \\
\hline \multicolumn{8}{|c|}{ Acesso } \\
\hline \multicolumn{8}{|l|}{ Atenção básica } \\
\hline Percentual de pessoas cobertas pelo PSF & 6,6 & 8,8 & 17,4 & 25,4 & 31,9 & 35,7 & 39,0 \\
\hline $\begin{array}{l}\text { Percentual de pessoas que têm posto ou } \\
\text { centro de saúde como serviço de uso regular. }\end{array}$ & 41,8 & - & - & - & - & 52,5 & - \\
\hline $\begin{array}{l}\text { Percentual de pessoas que consultaram } \\
\text { médico nos últimos } 12 \text { meses }\end{array}$ & 54,7 & - & - & - & - & 62,8 & - \\
\hline $\begin{array}{l}\text { Percentual de pessoas que consultaram } \\
\text { dentista nos últimos } 12 \text { meses }\end{array}$ & 33,1 & - & - & - & - & 38,7 & - \\
\hline $\begin{array}{l}\text { Percentual de mulheres ( } 25-59 \text { anos) que } \\
\text { fizeram teste de Papanicolau nos últimos três } \\
\text { anos }\end{array}$ & - & - & - & - & - & 74,2 & \\
\hline $\begin{array}{l}\text { Percentual de pessoas ( } 60 \text { anos ou mais) } \\
\text { imunizadas contra influenza }\end{array}$ & - & - & 67,5 & 73,1 & 74,1 & 82,1 & 85,5 \\
\hline
\end{tabular}


Tabela 1. continuação

\begin{tabular}{|c|c|c|c|c|c|c|c|}
\hline & 2005 & 2006 & 2007 & 2008 & 2009 & 2010 & Fonte \\
\hline \multicolumn{8}{|c|}{ Efetividade } \\
\hline \multicolumn{8}{|l|}{ Mortes evitáveis } \\
\hline $\begin{array}{l}\text { Taxa de mortalidade por hipertensão } \\
\text { padronizada pos sexo e idade para cada } 100 \\
\text { mil habitantes ( } 50 \text { a } 64 \text { anos) }\end{array}$ & 35,7 & 34,8 & 35,4 & 36,9 & 37,1 & - & SIM \\
\hline $\begin{array}{l}\text { Taxa de mortalidade por diabete melito } \\
\text { padronizada por sexo e idade para cada } 100 \\
\text { mil habitantes com ( } 30 \text { anos ou mais) }\end{array}$ & 47,8 & 52,8 & 52,4 & 53,9 & 53,8 & - & SIM \\
\hline $\begin{array}{l}\text { Taxa de mortalidade por diarreia para cada } \\
100 \text { mil habitantes menores de } 5 \text { anos. }\end{array}$ & 15,3 & 13,4 & 9,9 & 9,1 & 8,1 & - & SIM \\
\hline $\begin{array}{l}\text { Taxa de mortalidade por IRA para cada } 100 \\
\text { mil crianças menores de } 5 \text { anos. }\end{array}$ & 19,0 & 18,2 & 17,5 & 16,8 & 17,4 & - & SIM \\
\hline \multicolumn{8}{|l|}{ Incidência de doenças evitáveis } \\
\hline $\begin{array}{l}\text { Taxa de incidência de AIDS para cada } 100 \\
\text { mil habitantes. }\end{array}$ & 19,3 & 18,1 & 17,9 & 18,2 & 19,7 & & RIPSA \\
\hline $\begin{array}{l}\text { Taxa de incidência de tuberculose para cada } \\
100 \text { mil habitantes. }\end{array}$ & 41,5 & 38,9 & 38,1 & 37,5 & 38,4 & - & RIPSA \\
\hline \multicolumn{8}{|l|}{$\begin{array}{l}\text { Internações evitáveis por condições sensíveis à } \\
\text { atenção primária }\end{array}$} \\
\hline $\begin{array}{l}\text { Percentual de internações por Condições } \\
\text { Sensíveis à Atenção Primária (todas as } \\
\text { condições). }\end{array}$ & 24,8 & 24,8 & 24,1 & 22,6 & 22,5 & 22,5 & $\mathrm{SIH}$ \\
\hline $\begin{array}{l}\text { Taxa de internação por gastroenterite } \\
\text { padronizada por sexo e idade para cada } 100 \\
\text { mil habitantes. }\end{array}$ & 313,9 & 316,5 & 263,4 & 334,8 & 308,7 & 356,0 & $\mathrm{SIH}$ \\
\hline $\begin{array}{l}\text { Taxa de internação por insuficiência cardíaca } \\
\text { padronizada por sexo e idade para cada } 100 \\
\text { mil habitantes com } 40 \text { anos ou mais. }\end{array}$ & 704,0 & 635,3 & 591,7 & 412,0 & 403,0 & 373,8 & $\mathrm{SIH}$ \\
\hline $\begin{array}{l}\text { Taxa de internação por asma padronizada por } \\
\text { sexo e idade para cada } 100 \text { mil habitantes. }\end{array}$ & 164,0 & 148,7 & 149,1 & 119,1 & 117,6 & 118,1 & $\mathrm{SIH}$ \\
\hline $\begin{array}{l}\text { Taxa de internação por pneumonia } \\
\text { bacteriana padronizada por sexo e idade para } \\
\text { cada } 100 \text { mil habitantes ( } 18 \text { anos ou mais) }\end{array}$ & 50,4 & 51,2 & 45,8 & 41,2 & 44,4 & 45,4 & $\mathrm{SIH}$ \\
\hline \multicolumn{8}{|c|}{ Acesso } \\
\hline \multicolumn{8}{|l|}{ Atenção básica } \\
\hline Percentual de pessoas cobertas pelo PSF & 44,4 & 46,2 & 46,6 & 49,5 & 50,6 & - & SIAB \\
\hline $\begin{array}{l}\text { Percentual de pessoas que têm posto ou } \\
\text { centro de saúde como serviço de uso regular. }\end{array}$ & - & - & - & 56,8 & - & - & PNAD \\
\hline $\begin{array}{l}\text { Percentual de pessoas que consultaram } \\
\text { médico nos últimos } 12 \text { meses }\end{array}$ & - & - & - & 67,7 & - & - & PNAD \\
\hline $\begin{array}{l}\text { Percentual de pessoas que consultaram } \\
\text { dentista nos últimos } 12 \text { meses }\end{array}$ & - & - & - & 40,2 & - & - & PNAD \\
\hline $\begin{array}{l}\text { Percentual de mulheres (25-59 anos) que } \\
\text { fizeram teste de Papanicolau nos últimos três } \\
\text { anos }\end{array}$ & - & - & - & 79,3 & - & - & PNAD \\
\hline $\begin{array}{l}\text { Percentual de pessoas ( } 60 \text { anos ou mais) } \\
\text { imunizadas contra influenza }\end{array}$ & 84,1 & 85,7 & 76,0 & 75,1 & 82,7 & 84,9 & PNI \\
\hline
\end{tabular}


Tabela 1. continuação

\begin{tabular}{|c|c|c|c|c|c|c|c|}
\hline & 1998 & 1999 & 2000 & 2001 & 2002 & 2003 & 2004 \\
\hline \multicolumn{8}{|c|}{ Acesso } \\
\hline \multicolumn{8}{|l|}{ Média e alta complexidade } \\
\hline $\begin{array}{l}\text { Percentual de mulheres ( } 50 \text { a } 69 \text { anos) que } \\
\text { fizeram mamografia nos últimos três anos }\end{array}$ & - & - & - & - & - & 46,0 & \\
\hline $\begin{array}{l}\text { Taxa de cirurgias de prótese parcial ou total } \\
\text { de quadril padronizada por sexo e idade em } \\
\text { pessoas com } 65 \text { anos ou mais por } 100 \mathrm{mil} \\
\text { residentes }\end{array}$ & 74,7 & 86,3 & 82,1 & 84,1 & 85,1 & 93,9 & 95,7 \\
\hline $\begin{array}{l}\text { Taxa de angioplastia padronizada por sexo e } \\
\text { idade para cada } 100 \text { mil habitantes ( } 40 \text { anos } \\
\text { ou mais) }\end{array}$ & 27,0 & 31,5 & 39,8 & 49,5 & 55,1 & 57,6 & 58,2 \\
\hline $\begin{array}{l}\text { Taxa bruta de facectomias por } 100 \mathrm{mil} \\
\text { habitantes ( } 40 \text { anos ou mais) }\end{array}$ & - & - & 443,6 & 567,9 & 697,7 & 638,2 & 654,5 \\
\hline \multicolumn{8}{|c|}{ Eficiência } \\
\hline $\begin{array}{l}\text { Percentual de vasectomias feitas em } \\
\text { ambulatório ou internação }<1 \text { dia }\end{array}$ & - & - & 81,7 & 83,7 & 81,9 & 79,5 & 86,7 \\
\hline $\begin{array}{l}\text { Percentual de cirurgias de catarata feitas em } \\
\text { ambulatório ou internação }<1 \text { dia }\end{array}$ & - & - & 84,1 & 90,0 & 93,8 & 94,2 & 94,9 \\
\hline $\begin{array}{l}\text { Percentual de amigdalectomias e } \\
\text { adenoidectomias feitas em ambulatório ou } \\
\text { internação }<1 \text { dia }\end{array}$ & - & - & 20,4 & 25,2 & 31,3 & 32,1 & 31,5 \\
\hline $\begin{array}{l}\text { Percentual de hemorroidectomias feitas em } \\
\text { internação }<1 \text { dia }\end{array}$ & - & - & 1,8 & 2,2 & 3,1 & 3,3 & 4,1 \\
\hline
\end{tabular}

\section{Adequação}

Atenção Básica

Percentual de meningites bacterianas que tiveram confirmação diagnóstica

laboratorialmente

Percentual de nascidos vivos cujas mães

fizeram 7 ou mais consultas de pré-natal.

Média e alta Complexidade

Taxa padronizada de internação para

histerectomia em mulheres (20 anos ou

mais), padronizada por idade

Tempo médio de permanência hospitalar em pacientes com fratura no quadril (50 anos ou mais)

Percentual de partos cesáreos.

Razão entre hemodiálise e transplante renal Percentual de pacientes com AVC que realizam tomografia computadorizada nos primeiros sete dias de internação.

$\begin{array}{rrrrrrrr}- & - & - & 33,4 & 31,0 & 36,1 & 36,1 \\ 49,5 & 50,7 & 46,0 & 47,3 & 49,1 & 51,1 & 52,9 \\ & & & & & & \\ 118,6 & 132,3 & 123,9 & 125,9 & 116,3 & 118,1 & 116,3 \\ & & & & & & \\ 9,7 & 9,2 & 9,3 & 9,3 & 8,8 & 8,8 & 9,0 \\ & & & & & & \\ 38,4 & 37,2 & 38,0 & 38,3 & 38,8 & 40,1 & 41,8 \\ - & 26,7 & 25,5 & 23,6 & 26,5 & 26,7 & 25,0 \\ 19,5 & 20,5 & 22,1 & 19,9 & 19,9 & 22,1 & 24,9 \\ & & & & & & \end{array}$

Quanto às categorias de análise, as possibilidades variaram segundo o indicador e a fonte. Sempre que os dados permitiram, os indicadores foram obtidos para o país, grandes regiões e unidades da federação. Quando viável, foi adotado o recorte urbano / rural.

Um sistema desenvolvido para consulta via $\mathrm{WEB}^{27}$ permite a tabulação dos dados e a geração de tabelas e/ou gráficos para todos os indicadores.

\section{Indicadores de Efetividade}

Os indicadores de efetividade selecionados referem-se a resultados da intervenção dos serviços de saúde sobre a saúde da população. Foram contemplados 3 grupos:

a) indicadores que se referem a mortes evitáveis $^{28}$ através da atuação dos serviços de saúde, no âmbito da promoção, da prevenção e dos serviços médico-assistenciais. Segundo Simonato et al. ${ }^{29}$ são 
Tabela 1. continuação

\begin{tabular}{|c|c|c|c|c|c|c|c|}
\hline & 2005 & 2006 & 2007 & 2008 & 2009 & 2010 & Fonte \\
\hline & Acesso & & & & & & \\
\hline \multicolumn{8}{|l|}{ Média e alta complexidade } \\
\hline $\begin{array}{l}\text { Percentual de mulheres ( } 50 \text { a } 69 \text { anos) que } \\
\text { fizeram mamografia nos últimos três anos }\end{array}$ & - & - & - & 60,4 & - & - & PNAD \\
\hline $\begin{array}{l}\text { Taxa de cirurgias de prótese parcial ou total } \\
\text { de quadril padronizada por sexo e idade em } \\
\text { pessoas com } 65 \text { anos ou mais por } 100 \text { mil } \\
\text { residentes }\end{array}$ & 92,2 & 90,3 & 87,3 & 85,2 & 86,3 & 86,5 & $\mathrm{SIH}$ \\
\hline $\begin{array}{l}\text { Taxa de angioplastia padronizada por sexo e } \\
\text { idade para cada } 100 \text { mil habitantes ( } 40 \text { anos } \\
\text { ou mais) }\end{array}$ & 62,7 & 71,1 & 69,0 & 63,2 & 72,3 & 74,4 & $\mathrm{SIH}$ \\
\hline $\begin{array}{l}\text { Taxa bruta de facectomias por } 100 \mathrm{mil} \\
\text { habitantes ( } 40 \text { anos ou mais) }\end{array}$ & 663,6 & 398,1 & 427,5 & 129,7 & 116,2 & 96,1 & $\mathrm{SIH}$ \\
\hline \multicolumn{8}{|c|}{ Eficiência } \\
\hline $\begin{array}{l}\text { Percentual de vasectomias feitas em } \\
\text { ambulatório ou internação }<1 \text { dia }\end{array}$ & 88,7 & 86,2 & 84,7 & 79,1 & 81,3 & 81,7 & SIH e SIA \\
\hline $\begin{array}{l}\text { Percentual de cirurgias de catarata feitas em } \\
\text { ambulatório ou internação }<1 \text { dia }\end{array}$ & 95,0 & 86,9 & 88,5 & 97,9 & 94,6 & 93,7 & SIH e SIA \\
\hline $\begin{array}{l}\text { Percentual de amigdalectomias e } \\
\text { adenoidectomias feitas em ambulatório ou } \\
\text { internação }<1 \text { dia }\end{array}$ & 35,3 & 34,2 & 37,2 & 37,3 & 39,3 & 40,6 & SIH e SIA \\
\hline $\begin{array}{l}\text { Percentual de hemorroidectomias feitas em } \\
\text { internação }<1 \text { dia }\end{array}$ & 4,8 & 3,9 & 5,1 & - & - & - & SIH e SIA \\
\hline \multicolumn{8}{|c|}{ Adequação } \\
\hline \multicolumn{8}{|l|}{ Atenção Básica } \\
\hline $\begin{array}{l}\text { Percentual de meningites bacterianas que } \\
\text { tiveram confirmação diagnóstica } \\
\text { laboratorialmente }\end{array}$ & 38,0 & 37,3 & 47,4 & 49,8 & 50,4 & 52,8 & SINAN \\
\hline $\begin{array}{l}\text { Percentual de nascidos vivos cujas mães } \\
\text { fizeram } 7 \text { ou mais consultas de pré-natal. }\end{array}$ & 53,6 & 55,4 & 56,6 & 57,7 & 58,5 & - & SINASC \\
\hline \multicolumn{8}{|l|}{ Média e alta Complexidade } \\
\hline $\begin{array}{l}\text { Taxa padronizada de internação para } \\
\text { histerectomia em mulheres ( } 20 \text { anos ou } \\
\text { mais), padronizada por idade }\end{array}$ & 119,7 & 124,3 & 124,8 & 104,2 & 103,6 & 105,2 & $\mathrm{SIH}$ \\
\hline $\begin{array}{l}\text { Tempo médio de permanência hospitalar em } \\
\text { pacientes com fratura no quadril ( } 50 \text { anos ou } \\
\text { mais) }\end{array}$ & 8,8 & 8,7 & 8,9 & 8,4 & 8,6 & 8,8 & $\mathrm{SIH}$ \\
\hline Percentual de partos cesáreos. & 43,3 & 45,1 & 46,6 & 48,4 & 50,1 & - & SINASC \\
\hline Razão entre hemodiálise e transplante renal & 26,2 & 30,8 & 29,2 & - & - & - & RIPSA e SIH \\
\hline $\begin{array}{l}\text { Percentual de pacientes com AVC que } \\
\text { realizam tomografia computadorizada nos } \\
\text { primeiros sete dias de internação. }\end{array}$ & 26,2 & 19,7 & 25,2 & - & - & - & SIH \\
\hline
\end{tabular}

mortes evitáveis: (i) aquelas evitáveis por serem decorrentes de agravos passíveis de prevenção através da atenção primária em saúde e outras políticas sociais, agravos esses referentes fundamentalmente a estilos de vida; (ii) as mortes por causas prevenidas através de detecção precoce e tratamento oportuno (neoplasias malignas, dentre outras); (iii) as mortes evitáveis por agravos sensíveis ao cuidado médico-assistencial adequado. b) Indicadores que remetem à incidência de algumas doenças evitáveis através de ações do sistema de saúde. O conceito de "morbidade evitável" foi proposto por vários autores ${ }^{25}$ e remete a casos que poderiam ser prevenidos (evitados) através de intervenções em saúde efetivas, principalmente as relacionadas à atenção primária.

c) Indicadores referentes a internações evitáveis. O conceito de internações evitáveis - ou in- 
ternações por condições sensíveis à atenção primária - proporciona uma medida indireta da efetividade da atenção primária, pois trata-se de internações por condições sensíveis nesse nível de atenção. Segundo Billings et al. ${ }^{30}$, uma atenção ambulatorial efetiva e oportuna pode ajudar a reduzir os riscos de hospitalização, tanto por prevenir o estabelecimento da doença ou condição, como por controlar o surgimento de episódios agudos por condições crônicas. Note-se que o Brasil já possui uma lista nacional de condições sensíveis à atenção primária, utilizada para o cálculo do indicador referente ao conjunto desse tipo de internações.

\section{Indicadores de Acesso}

Na matriz conceitual do PROADESS, acesso é definido como a capacidade do sistema de saúde em prover o cuidado e o serviço necessário, no momento certo e no lugar adequado. Cabe destacar que, assim como em outros países, os indicadores trabalhados contemplam apenas parcialmente a definição proposta pelo PROADESS para avaliação do acesso, já que não é possível avaliar se o acesso foi feito em tempo oportuno. Também quanto ao local oportuno, os indicadores usados não sugerem nem que o acesso tenha sido no local apropriado e tampouco apontam para barreiras físicas.

Tendo como referência os indicadores utilizados por outros países e por organizações internacionais, fez-se uma avaliação da viabilidade de obtê-los no caso brasileiro a partir das fontes de dados existentes, considerando-se dois níveis de atenção: atenção básica e atenção de média/ alta complexidade.

Com relação à atenção básica, verificou-se que dados de inquéritos populacionais seriam mais adequados por permitirem análises sobre a equidade no acesso, uma vez que podem gerar indicadores para diferentes grupos populacionais definidos pela sua inserção social. No caso dos indicadores de média e alta complexidades, utilizaram-se dados do sistema de informação de internações hospitalares $(\mathrm{SIH})$ e de inquéritos populacionais. A informação do SIH não considera procedimentos realizados pelo sistema privado, a menos que as internações tenham sido financiadas pelo SUS. O único recorte populacional possível foi o geográfico, enquanto que as informações dos inquéritos permitem analisar as desigualdades sociais e geográficas no acesso.

\section{Indicadores de Eficiência}

Considerando que além dos insumos e custos envolvidos na produção dos cuidados de saúde, outros fatores intervêm na eficiência - a necessidade e a adequação do tratamento e a efetividade dos resultados ${ }^{24}$, um indicador de eficiência é dado pelas internações por procedimentos factíveis de serem realizados em nível ambulatorial.

O indicador utilizado para dimensionar a eficiência dos serviços de saúde no Brasil foi a proporção de cirurgias realizadas em regime ambulatorial e hospitalar, com menos de 1 dia de permanência.

Para avaliar a eficiência dos serviços de saúde no Brasil foram escolhidos cinco procedimentos cirúrgicos considerados, pelo NHS-UK, passíveis de serem efetuados em ambulatórios, ou day case: vasectomia, cirurgia de cataratas, amigdalectomia/adenoidectomia e hemorroidectomia. Esses procedimentos foram selecionados em função de sua maior frequência.

Apesar de a eficiência ser definida como a otimização dos recursos disponíveis para produzir o máximo de benefícios e resultados, o indicador utilizado pela maior parte dos países selecionados refere-se ao tempo médio de permanência, estimado comparando o tempo médio de permanência observado em relação ao esperado, ajustado pelo casemix. Os resultados obtidos em trabalhos realizados no Brasil apontam para sua alta homogeneidade, provavelmente decorrente da insuficiência de informações para efetuar o ajuste pelo casemix. Nesse caso, tempos médios de permanência mais longos podem indicar maior gravidade dos casos ou baixa eficiência, e tempos de permanência mais curtos podem ser motivados por altas precoces, ou maior eficiência técnica ${ }^{31}$.

\section{Indicadores de Adequação}

No âmbito do PROADESS o conceito de adequação adotado foi o mesmo definido pela $\mathrm{JCAHO}^{14}$ que considera o grau de relevância de uma intervenção ou cuidado prestado para as necessidades clínicas dos pacientes, dados o conhecimento existente e o uso de práticas baseadas em conhecimentos técnicos bem fundamentados. A revisão dos indicadores utilizados por outros países permitiu identificar que os mais utilizados são relativos à média/alta complexidade. Considerando-se a importância da atenção básica no sistema de saúde brasileiro foi necessário definir alguns indicadores que permitissem avaliar a adequação do cuidado nesse nível de atenção. Para tanto, foram selecionados dois 
indicadores: o percentual de meningites bacterianas com confirmação laboratorial, e o percentual de nascidos vivos cujas mães fizeram sete ou mais consultas de pré-natal.

Para a alta/média complexidade foram selecionados indicadores trabalhados por outros países e organismos internacionais, como taxas de histerectomia, percentual de parto cesáreo e tempo médio de internação para fratura de quadril. A taxa padronizada de histerectomia foi calculada para as mulheres de 20 anos ou mais submetidas ao procedimento devido a uma doença benigna. $\mathrm{O}$ tempo médio de permanência para fratura do quadril foi obtido para a população de 50 anos e mais.

Além desses, foram incluídos o percentual de internações por AVC nas quais foi realizada uma tomografia nos primeiros 7 dias, e a razão entre pacientes submetidos a diálise e a transplantes renais.

\section{Resultados}

$\mathrm{Na}$ Tabela 1 apresentam-se os resultados dos indicadores para as subdimensões do desempenho de serviços de saúde no Brasil para o período analisado em cada caso.

No que se refere aos indicadores de efetividade, os indicadores relativos a mortes evitáveis também sugerem dois tipos de resultados. Há uma nítida tendência à diminuição da mortalidade em menores de 5 anos por causas associadas à diarreia e por infecções respiratórias agudas. No caso da mortalidade por hipertensão e diabetes mellitus, houve um pequeno aumento nos dois últimos anos analisados.

Quando se analisam as taxas de incidência por doenças evitáveis, observa-se uma estabilidade no caso da AIDS e uma leve diminuição na taxa de incidência de tuberculose a partir de 2006. Quando a efetividade é avaliada a partir das internações por algumas causas sensíveis à atenção primária, observa-se uma melhoria no desempenho na insuficiência cardíaca, na asma e na pneumonia bacteriana. O melhor resultado foi observado para a insuficiência cardíaca, condição para a qual há uma queda de $66 \%$ na taxa de internação hospitalar ao longo do período.

No que se refere ao acesso na atenção básica, o aumento na proporção de pessoas que referem ter consultado médicos e dentistas nos últimos 12 meses, e as altas coberturas alcançadas para o exame de Papanicolau e de imunização de idosos contra influenza são indicativos de que o acesso aos serviços vem aumentando ao longo de período analisado. Essa melhoria no acesso é coerente com o aumento da cobertura do PSF e com o aumento no percentual de pessoas que declararam usar o posto ou o centro de saúde como serviço de uso regular entre 1998 e 2008. Entretanto, apesar dos aumentos verificados, apenas $40 \%$ das pessoas, em 2008, consultaram dentista nos últimos 12 meses.

No acesso a serviços de média e alta complexidade verificam-se situações distintas. Por um lado um aumento importante no percentual de mulheres (50 - 69 anos) que fizeram mamografia nos últimos três anos e na taxa de utilização de angioplastia em pessoas de 40 anos e mais. Por outro lado, a taxa padronizada de prótese parcial ou total de quadril em pessoas com 65 anos e mais se manteve praticamente estável no período 1999 a 2010. Uma situação particular é o da evolução da taxa de realização de cirurgia de catarata (facectomias) que, depois de um aumento importante entre 2002 e 2005, tem uma tendência acentuada de diminuição. O aumento evidenciado foi decorrente da alocação de recursos específicos que não poderiam ser usados para outros propósitos, política adotada para alguns procedimentos considerados prioritários com o objetivo de atender a demanda reprimida.

A eficiência no desempenho dos serviços foi estimada pelo percentual de procedimentos realizados em regime ambulatorial ou hospitalar de menos de um dia de permanência, para quatro dos vinte e dois procedimentos cirúrgicos considerados pelo sistema nacional de saúde britânico como passíveis de serem efetuados em ambulatórios, ou day case: vasectomia, cirurgia de cataratas, amigdalectomia/adenoidectomia e hemorroidectomia. Os procedimentos foram selecionados em função de sua maior frequência.

No período de 2000 a 2010, os percentuais de vasectomias realizadas em ambulatório ou em regime de internação de menos de um dia foram superiores a $80 \%$ na maior parte dos anos.

O percentual de cirurgias de cataratas realizadas em ambulatórios, ou em regime hospitalar de menos de um dia de permanência, aumentou de maneira importante entre 2000 e 2002. Após quatro anos de certa estabilidade, diminuiu de forma acentuada em 2006, retornando nos últimos três aos patamares do início da década de 2000.

Pior desempenho é observado no que se refere ao percentual de amigdalectomias e adenoidectomias realizadas em ambulatórios ou regime hospitalar de menos de um dia de permanên- 
cia, pois se observam no país valores ainda baixos $(40,6 \%$ em 2010). Também uma baixa eficiência é observada em relação ao percentual de hemorroidectomias realizadas em regime ambulatorial ou hospitalar com menos de um dia de permanência, que se manteve baixo (em torno de $14 \%$ ) até 2007. Nos últimos três anos, esse percentual fica em torno de $5 \%$.

Na subdimensão adequação foram considerados os indicadores para a atenção básica e a de alta/média complexidade. $\mathrm{Na}$ atenção básica, o percentual de meningites bacterianas confirmadas laboratorialmente indica um baixo desempenho dos serviços no início da década, com o aumento significativo nos últimos quatro anos. Quanto ao percentual de gestantes que relataram 7 ou mais consultas de pré-natal, verificou-se uma tendência crescente chegando a 58,5\% em 2009.

Na média e alta complexidade a evolução temporal da maior parte dos indicadores selecionados para avaliar a adequação do cuidado (tempo médio de permanência para internações por fratura de quadril, percentual de parto cesáreo, razão entre pacientes em diálise e transplantes renais, percentual de internações por AVC com tomografia) sugere que, para o país como um todo, não houve melhora no desempenho dos serviços, à exceção da taxa de histerectomia, que diminuiu nos últimos três anos. No caso do percentual de partos cesáreos os valores registrados demonstram uma piora no desempenho, sendo que 50,1\% dos partos realizados em 2009 foram cirúrgicos. $\mathrm{O}$ único indicador que apresentou uma evolução favorável foi o tempo médio de permanência para internações por fratura de quadril, com uma redução de quase um dia entre 1998 e 2010.

\section{Conclusão}

O comportamento dos indicadores utilizados para avaliar o desempenho dos serviços de saúde no Brasil, no que se refere às quatro subdimensões selecionadas, não é uniforme e as melhorias mais acentuadas são observadas naqueles influenciados pela atuação dos serviços no campo da atenção primária, com as mais significativas observadas nas subdimensões Efetividade e Acesso.

No que concerne aos indicadores de efetividade, o desempenho do sistema de saúde brasileiro melhorou substantivamente nas internações por condições evitáveis através da atenção primária, como asma e insuficiência cardíaca. Ainda, o sistema exibiu grandes melhoras no que tange à mortalidade de crianças associada à di- arreia e às infecções respiratórias agudas. Essa redução das internações e das mortes evitáveis através da atenção primária está provavelmente associada à expansão do Programa de Saúde da Família. Entretanto, o mesmo não se verificou no que tange ao resultado da atenção a certos grupos de doenças crônicas, tendo em vista o aumento da mortalidade por hipertensão e diabetes, que pode inclusive ser devido à expansão da oferta e mudanças nos sistemas de registro de informações. Segundo o Ministério da Saúde brasileiro, a partir de 2007 há um aumento na incidência de aids entre jovens do sexo masculino de 15 a 24 anos $^{32}$.

Deve-se mencionar a existência de alguns indicadores de efetividade propostos mais recentemente por sistemas de avaliação de desempenho de outros países e de organismos internacionais para os quais não há disponibilidade de informações no Brasil. É o caso de indicadores referentes à taxa de reinternação pós-alta hospitalar por causas específicas e os relacionados à sobrevida para algumas condições específicas (neoplasias malignas, IAM, etc.)

No que se refere ao acesso, verificou-se no país, na última década, uma importante ampliação do mesmo, retratada por todos os indicadores analisados, para atenção básica e média/alta complexidade, excetuando os resultados verificados no caso da taxa de cirurgias de prótese de quadril, que permaneceu estável no período.

Embora não tenha sido apresentado nos resultados, as informações disponíveis indicam que as desigualdades sociais no acesso aos cuidados de saúde diminuíram no que concerne aos serviços de menor complexidade (consultas médicas e odontológicas, exame papanicolau, por exemplo), certamente como resultado da mudança no modelo de atenção à saúde. Também se deu uma redução importante nas desigualdades entre as áreas rurais e urbanas, como, por exemplo, a cobertura do exame de Papanicolau ${ }^{26}$. Grandes desigualdades regionais persistem no acesso aos serviços de mais alta complexidade, tais como a angioplastia e o implante de prótese de quadril, provavelmente em função das desigualdades regionais da oferta desses serviços.

No que se refere à dimensão eficiência, a análise dos indicadores utilizados indica diferentes níveis nos serviços de saúde no Brasil. Bom desempenho em relação aos percentuais de vasectomias e à porcentagem de cirurgias de cataratas, e baixo no que se refere ao percentual de amigdalectomias, de adenoidectomias e de hemorroidectomias. 
Pode-se afirmar, em relação aos procedimentos realizados predominantemente em âmbito de internação, que eles são baixos provavelmente motivados pela falta de oferta ambulatorial adequada. Questões culturais podem também estar influenciando as baixas porcentagens de produção em ambulatórios ou em regime de internação de menos de um dia. Outros fatores que podem estar afetando os resultados são as diferenças existentes na remuneração entre os regimes em que é realizado o procedimento, sendo os valores sempre mais elevados no de internação, e também as mudanças na tabela de procedimentos, conforme observado no percentual de hemorroidectomias com a supressão do código exerese de trombose hemorroidária.

Portanto, coexistem no Brasil situações de alta eficiência com outras de baixo desempenho, evidenciando espaços para a implementação de reformas na busca da diminuição dos custos e na liberação de leitos para outros usos e tratamento dos pacientes num ambiente mais apropriado.

O desempenho do sistema de saúde brasileiro na subdimensão adequação foi pior do que nas demais apresentadas. Por exemplo, a taxa de histerectomia em mulheres com diagnóstico de doença benigna encontra-se alta, porém nota-se uma queda importante nos últimos três anos. A magnitude do percentual de cesarianas observada no Brasil também aumentou significativamente. Além disso, o desempenho do sistema deixa a desejar no que se refere ao indicador de atenção ao AVC, tendo em vista que em apenas um quarto das internações por essa causa foi realizado o exame de tomografia. Houve ainda uma pequena piora na razão entre o número de pacientes em terapia renal substitutiva e o número de transplantes renais realizados. $\mathrm{O}$ indicador de adequação com melhor desempenho refere-se ao número de consultas de pré-natal.

É necessário destacar que a análise do desempenho do sistema de saúde, à luz dos resultados apresentados, contém algumas limitações.

Os indicadores apresentados referem-se exclusivamente à média nacional e, portanto, não refletem as desigualdades regionais existentes. Deve-se destacar que a maior parte dos indicadores apresenta pior desempenho nas Regiões Norte e Nordeste. Também existem situações dispares entre os Estados de uma mesma Região. Ainda, as baixas frequências de procedimentos de média/alta complexidade observadas na Região Norte provocam oscilações nas séries temporais que dificultam a identificação de tendências na Região ${ }^{26}$.
Deve-se mencionar também o fato de que a maior parte dos indicadores, à exceção de os relativos ao acesso e de alguns de adequação, refere-se apenas ao desempenho do SUS - e não do sistema de saúde como um todo - tendo em vista a falta de informações sistematizadas sobre o que ocorre na atenção à saúde provida pelo segmento de planos e seguros de saúde.

Outra limitação da análise diz respeito ao fato de os sistemas de informação de internações hospitalares (SIH) e de atendimento ambulatorial (SIA) apresentarem subregistro de informações sobre diagnósticos secundários, o que impediu a aplicação de ajustes segundo a presença de comorbidades (casemix) e, por conseguinte, maior controle dos fatores que explicariam as diferenças observadas em alguns indicadores.

Ainda, deve ser ressaltada a limitação da análise das desigualdades sociais contidas nos indicadores estudados. Somente aqueles calculados a partir da PNAD permitem tal análise, tendo em vista que as demais bases de dados não contêm campos relativos às condições socioeconômicas dos indivíduos. Nesse sentido, é necessário reconhecer e destacar a importância da realização de inquéritos populacionais, imprescindíveis para o levantamento de informações que permitam desenvolver a análise das desigualdades sociais ainda fortemente presentes no país.

Finalmente, é necessário explicitar que ainda não foram exploradas as associações entre as diversas dimensões da matriz conceitual do PROADESS, que serão objeto de futuros trabalhos. Uma vertente que parece ser promissora é a exploração do desempenho dos serviços de saúde tendo presentes os resultados referentes aos indicadores de estrutura. Da mesma forma, será interessante analisar as condições de saúde à luz dos resultados observados nos indicadores referentes aos determinantes sociais da saúde e dimensionar o papel que pode ser atribuível ao desempenho do sistema de saúde.

\section{Colaboradores}

F Viacava, MAD Ugá, S Porto, J Laguardia e RS Moreira participaram igualmente de todas as etapas de elaboração do artigo. 


\section{Referências}

1. Viacava F, Almeida C, Caetano R, Fausto M, Macinko J, Martins M, José Noronha JC, Novaes HMD, Oliveira ES, Porto SM, Silva LMV, Szwarcwald CL. Uma metodologia de avaliação do desempenho do sistema de saúde brasileiro. Cien Saude Colet 2004; 9(3):711-724.

2. Facchini LA, Piccini RX, Tomasi E, Thumé E, Teixeira VA, Silveira DS, Maia MFS, Siqueira FV, Rodrigues MA, Paniz VV, Osório A. Avaliação de efetividade da Atenção Básica à Saúde em municípios das regiões Sul e Nordeste do Brasil: contribuições metodológicas. Cad Saude Publica 2008; 24(Supl. 1):S159-S172.

3. Vuori H. A qualidade da Saúde. Divulgação em Saúde para Debate 1991; 3:17-25.

4. Donabedian A. The seven pillars of quality. Arch Pathol Lab Med 1990; 114(11):1115-1118.

5. The Joint Commission on Accreditation of Healthcare Organizations (JCAHO). The Measurement Mandate: on the Road Performance Improvement in Health Care. Chicago: The Joint Commission on Accreditation of Healthcare Organizations (JCAHO); 1993.

6. Institute of Medicine of the National Academies (IOM). Committee on Quality of Health Care in America. Crossing the Quality Chasm: a new health system for the 21 st century. Washington: National Academies Press; 2001

7. Frenk J. The concepts and measurement of accessibility. In: White K, Frenk J, Ordoñez Carceller C, Paganini MF, Starfield B, editors. Health Services Research: an Anthology. Washington: PAHO; 1992. p. 842-855.

8. Donabedian A. Aspects of Medical Care Administration. Boston: Harvard University Press; 1973.

9. Wörz M, Foubister T, Busse R. Access to health care in the EU Member States. Euro Observer 2006; $8(2): 1-4$.

10. Travassos CM, Martins M. Uma revisão sobre os conceitos de acesso e utilização de serviços de saúde. Cad Saude Publica 2004; 20(Supl.2):S190-S198.

11. Jesus WLA, Assis MMA. Revisão sistemática sobre o conceito de acesso nos serviços de saúde: contribuições do planejamento. Cien Saude Colet 2010; 15(1):161-170.

12. Hussey PS, De Vries H, Romley J, Wang MC, Chen SS, Shekelle PG, McGlynn EA. A Systematic Review of Health Care Efficiency Measures. HSR 2009; 44(3):784-805.

13. Binder LF, Rudolph B. Commentary: A Systematic Review of Health Care Efficiency Measures. HSR 2009; 44(3):806-811.

14. Organization for Economic Co-operation and Development (OECD). Health at a Glance 2009: OECD Indicators. Paris: OECD Publishing; 2009.

15. The Joint Commission on Accreditation of Healthcare Organizations (JCAHO). National Library of Healthcare Indicators. Health Plan and Network Edition. Oakbrook Terrace: Joint Commission on Accreditation of Healthcare Organizations (JCAHO); 1997.

16. Kelley E, Hurst J. Health Care Quality Indicators Project: Conceptual Framework Paper. OECD Health Working Papers No 23. Paris: OECD Publishing; 2006.
17. The Australian Institute for Health and Welfare (AIHW). Australia's Health, 2010. Cat. no. AUS 122. Canberra: The Australian Institute for Health and Welfare (AIHW); 2010

18. Chassin MR, Galvin RW and The National Roundtable on Health Care Quality. The Urgent Need to Improve Health Care Quality: IOM National Roundtable on Health Care Quality. JAMA 1998; 280(11): 1000-1005.

19. Aday LA, Begley CE, Lairson DR, Balkrishnan R. Evaluating the healthcare system: effectiveness, efficiency, and equity. $3^{\text {rd }}$ ed. Chicago: Health Administration Press; 2004.

20. Smith P, Mossialos E, Papanicolas I. Performance measurement for health system improvement: experiences, challenges and prospects. Copenhagen: WHO Regional Office for Europe; 2008.

21. Sharpe VA, Faden AI. Appropriateness in patient care: a new conceptual framework. The Mildbank Quarterly 1996; 74(1):115-138.

22. Naylor CD. What is Appropriate Care. $N$ Engl J Med 1998; 338(26):1918-1920.

23. Berg M, Meulen RT, van den Burg M. Guidelines for Appropriate Care: The Importance of Empirical Normative Analysis. Health Care Analysis 2001; 9(1):77-99.

24. Long AF, Harrison S, editors. Health Services Performance: Effectiveness and Efficiency. New South Wales: Croom Helm LTD; 1985.

25. Sheering I, Allen G, Henare M, Craig K. Avoidable hospitalizations: potential for primary and public health initiatives in Canterbury, New Zealand. N Z Med J 2006: 119(1236):U2029.

26. Klassen A, Miller A, Anderson N, Shen J, Schiariti V, O’Donnel M. Performance measurement and improvement frameworks in health, education and social services systems: a systematic review. Int $J$ Qual Health Care 2010; 22(1):44-69.

27. Viacava F, Porto SM, Laguardia J, Ugá AD, Moreira RS. Proadess: Avaliação de Desempenho do Sistema de Saúde Brasileiro: indicadores para monitoramento. [página na Internet]. Relatório final, 2011. [acessado 2012 mar 14]. Disponível em: http://www. proadess.icict.fiocruz.br

28. Nolte E, McKee M. Does health care save lives? Avoidable mortality revisited. London: The Nuffield Trust; 2004

29. Simonato L, Ballard T, Bellini P, Winkelmann R. Avoidable mortality in Europe 1955-1994: a plea for prevention. J Epidemiol Community Health 1998; 52(10):624-630.

30. Billings J, Zeitel L, Lukomnik J, Carey TS, Blank AE, Newman L. Impact of Socioeconomic Status on Hospital Use in New York City. Health Affairs 1993; 12(1):162-173.

31. Martins M, Blais R e Leite IC. Mortalidade hospitalar e tempo de permanência: comparação entre hospitais públicos e privados na região de Ribeirão Preto, São Paulo, Brasil. Cad Saude Publica 2004; 20(Sup.2):S268-S282.

32. Brasil. Ministério da Saúde (MS). Boletim Epidemiológico Aids/DST 2011; VIII(1):26.

Artigo apresentado em 23/11/2011

Aprovado em 15/12/2011

Versão final apresentada em 10/01/2012 